\title{
USE OF PLANT MATERIALS AS SOURCES FOR INULINASE PRODUCTION BY Aspergillus SP. STRAINS
}

Huka, F. I. A.*; A. A.E. Sleem*; M. M. A. El-Sawah*; A. Z. M. Ali** and M. K. M. Mahmoud**

* Microbiology Dept., Fac. Agric., Mansoura Univ., Mansoura , Egypt.

** Microbiology Dept., Soils water and Environment Research Institute (ARC) Egypt.

\begin{abstract}
Five fungal strains namely Aspergillus niger 6A, A. niger NRRL, A. niger NRC, $A$. fumigatus and $A$. oryzae were used in this study. Five different plant materials which underground roots and tubers were directly used in powder form as natural sources. They were chicory (Cichorium intibus), dahlia (Dahlia pinnata), Girasole or jurusalem artichoke (Helianthus tuberosus), suger beet (Beta vulgaris) and artichoke or Alkhrishv (Cynara cardunculus). Dahlia tubers and Girasole additions were the best inducer for inulinase production amongst other plant materials used. On the other hand, chicory, alkhrishv and sugar beet additions had negligible and/or negative effects on inulinase production by the tested fungal srtains.

Keywords : Aspergillus sp., Inulinase activity, Chicory, Dahlia, Girasole, Suger Beet and Alkhrishv.

\section{INTRODUCTION}

Inulinase is one of the key enzyme in the production of food industry such as high fructose syrup processing. The traditional production requires at least two enzymes to complete all processes and provide only $75 \%$ yield of product. However, if inulinase is used in this process, it can reduce both steps and gave $95 \%$ yield. Another important factor is the difficulty in harvesting enzyme from fungi. Fungal enzyme production is more complicated than bacteria due to hyphae. In addition, there is interest in ethanol production as alternative energy in the present by using inulinase producing bacteria and inulin-containing plant as substrate in fermentation process (Bonciu et al., 2010).

After starch, fructans are the most abundant non-structural polysaccharides found in a wide range of plants. Inulin is a polydispersed fructan consisting mainly of $\beta(2,1)$ fructoysl-fructose links terminated by a sucrose residue. It serves as a storage polysaccharide in many members of Liliaceae, Amaryllidaceae, Gramineae, Asteraceae, Compositae etc. and is accumulated in the underground roots and tubers of several plants including Jerusalem artichoke (Helianthus tuberosus), chicory (Cichorium intibus), dahlia (Dahlia pinnata) Jerusalem artichoke (Asparagus officinalis), and Dandelion (Taraxacum officinale) (Sharma \& Gill, 2007; Kango, 2008; Singh \& Bhermi, 2008 and Chi et al., 2011).

Microbial inulinases can be divided into exo- and endo-acting enzymes according to their modes of action on inulin. Endoinulinases (2,1- $\beta$-D-fructan fructanohydrolase; EC 3.2.1.7) are specific for inulin and hydrolyse the internal $\beta$-2,1-fructofuranosidic linkages to yield inulooligosaccharides as the main products, e.g. inulotriose, inulotetraose, and inulopentaose. Exoinulinases ( $\beta$ D-fructan fructohydrolase; EC 3.2.1.80) successively split off terminal fructose
\end{abstract}


Huka, F. I. A. et al.

units from the non-reducing end of inulin, and also hydrolyse sucrose and raffinose (Chen et al., 2009)

A number of fungal, yeast and bacterial strains have been reported for the production of inulinases. Amongst the filamentous fungi, Aspergillus species are the common inulinase producers and high inulinase producers (Singh and Singh, 2010).

The plant inulin is a renewable and abundant substrate for the microbial production of high fructose syrup, which has gained importance in food, drink and neutraceutical industries. Fructose is the sweetest natural sweetener and is 1.5-2 times sweeter than sucrose and is less cariogenic and has no bitter aftertaste of saccharin and hence can be used as an alternative sweetener for diabetics. Conventional fructose preparation from starch needs at least three enzymatic steps involving a-amylase, amyloglucosidase and glucose isomerase activities and maximal yields are reported to be $45 \%$ fructose solutions. An easier, direct, cheap and quicker alternative could be enzymatic hydrolysis of polydispersed reserve fructan, inulin (Kango, 2008).

This work aims to study the potent inulinase producing fungal strain on some vegetal substances.

\section{MATERIALS AND METHODS}

\section{Plant materials used}

Five different plant materials which have underground roots and tubers were collected from local markets were used in this study. Chicory (Cichorium intibus), dahlia (Dahlia pinnata), Girasole or jurusalem artichoke (Helianthus tuberosus), suger beet (Beta vulgaris) and artichoke or Alkhrishv (Cynara cardunculus).

\section{Fungal strains used:}

Five different fungal strains were used in this study. Two local fungal strains, namely Aspergillus oryzae and $A$. fumigatus; were kindly obtained from plant pathology Dept., Fac. of Agric., Mansoura Univ., Mansoura, Egypt. One strain, A. niger NRRL 2270; was obtained from Microbial Properties Research Unit, National Center for Agricultural Utilization Research, Agricultural Research Service, USA. Another one, A. niger NRC was kindly obtained from National Research Center (NRC) Giza, Egypt. The last one, namely A. niger 6A was kindly obtained from Agricultural Research Center (ARC) Giza, Egypt. These fungal strains were recommended as high producers for inulinase.

\section{Cultivation medium for inulinase production :}

The cultural medium was used as basal medium for inulinase production. The chemical composition of this medium was as following $(\mathrm{g} / \mathrm{l})$ : $\left(\mathrm{NH}_{4}\right)_{2} \mathrm{SO}_{4}, 0.5$; $\mathrm{KH}_{2} \mathrm{PO}_{4}, 3.0 ; \mathrm{NaNO}_{3}, 1.5 ; \mathrm{MgSO}_{4} .7 \mathrm{H}_{2} \mathrm{O}, 0.01$ and inulin, 3.0 with $\mathrm{pH}$ 7.0. Inulin was sterilized separately and added to the medium before inoculation (Kumar et al., 2005).

\section{Microbiological Methods:}

Pretreatment of plant materials as a source of inulin

The plant materials were washed in running tap water, sliced, and then dried at $70{ }^{\circ} \mathrm{C}$ for $72 \mathrm{~h}$. The dried slices were then milled to a fine powder with a hammer mill. After milling, the resultant powder was directly used as carbon source and inulin source (Dilipkumar et al., 2011). 
Maintainance of fungal strains:

The fungal strains were maintained on potato dextrose agar medium (PDA) slants at $5^{\circ} \mathrm{C}$ and monthly subcultured.

\section{Preparation of fungal spores suspension:}

Spores appeared on PDA slant after 7 days were scraped by using $5 \mathrm{~mL}$ sterilized saline solution containing $8 \mathrm{~g} \mathrm{NaCl} / \mathrm{L}$ and suspended in $45 \mathrm{~mL}$ of the same solution. Spores count was performed in a Hematocytometer (model Buerker MOM BUDA pest) direct hemocytometer counting. Spores suspention corresponding to approximately $5 \times 10^{6}$ spores per ml (Pintado et al., 1997).

\section{Inoculum size used:}

The inoculum size used was $1 \%$ for inoculating the cultivation medium for all experiments and the inoculum value was ontianed about $5 \times 10^{6}$ spores per $\mathrm{ml}$.

Inulinases production:

Inulinases production was carried out by submerged fermentation using $250 \mathrm{ml}$ Erlenmeyer flasks each containing $50 \mathrm{ml}$ of cultivation medium. After inoculation with $0.5 \mathrm{ml}$ of the tested fungal standard inoculum of spores suspension, the flasks were then incubated at $30^{\circ} \mathrm{C}$ for 6 days in a temperature controlled rotary incubator-shaker operated at $200 \mathrm{rpm}$. The fermented broth was filtered through double-layered Whatman paper filter. After filtration, the supernatant was collected as the crude enzyme solution for further studies (Chen et al., 2009).

\section{Biochemical determinations :}

Final pH:

Values of $\mathrm{pH}$ were determined in the cultural filtrate using a $\mathrm{pH}$ meter, model JENWAY 3505. The cultural filtrates were used for final $\mathrm{pH}$ determinations

\section{Determination of reducing sugar}

Reducing sugar in the fermented medium was determined by the Nelson-Somogyi method. Total sugar was measured as reduction of sugar after hydrolysis of the fermented medium (Cui et al., 2011). The residual reducing sugars were determined as fructose after Nelson, (1944). Standard curve of fructose was performed and the equation of inulinase activities was as follow : $\mathrm{X}(\mu \mathrm{g} / \mathrm{ml})=(\mathrm{Y}-0.0021) / 0.0591$

\section{Enzymatic activity}

The inulinase activity of the supernatant was determined as following: 0.5 $\mathrm{ml}$ cultural filtrate was incubated with $2.0 \mathrm{ml}$ of $0.2 \%$ inulin, $2.0 \mathrm{ml}$ acetate buffer (pH 4.6) at $40^{\circ} \mathrm{C}$ for $20 \mathrm{~min}$. (Cazetta et al., 2005). One unit of inulinase activity was defined as the amount of enzyme that hydrolyses $1 \mu \mathrm{g}$ fructose per min under the above conditions.

\section{RESULTS AND DISCUSSION}

Five fungal strains namely Aspergillus niger 6A, Aspergillus niger NRRL, Aspergillus niger NRC, Aspergillus fumigatus and Aspergillus oryzae were used in this study. Five different plant materials which underground roots and tubers collected from local markets were used directly in powder form as a natural source of inulin. They were Chicory (Cichorium intibus), Dahlia (Dahlia pinnata), Girasole 
Huka, F. I. A. et al.

or jurusalem artichoke (Helianthus tuberosus), suger beet (Beta vulgaris) and artichoke or Alkhrishv (Cynara cardunculus).

Effect of dahlia tubers addition on inulinase production by selected fungal srtains.

Table 1 show the effect of adding dahlia tubers on inulinase production by selected fungi. The highest values of inulinase production were $121.4,112,86.6,45.8$ and $56.4 \mu \mathrm{g}$ fructose $/ \mathrm{ml}$ after 144, 120, 96, 144 and 96 $\mathrm{h}$ of incubation period by Aspergillus niger 6A, A. niger NRC, A. niger NRRL, $A$. oryzae and $A$. fumigatus, respectively. These inulinase activities were correlated with,the final $\mathrm{pH}$ to be $6.11,6.20,4.18,6.73$ and 7.08 (Fig.1).

Table 1: Inulinase activities by selected fungal strains as induced by dahlia tubers.

\begin{tabular}{|l|c|c|c|c|c|}
\hline \multirow{2}{*}{ Fungal srtains } & \multicolumn{5}{|c|}{ Incubation period (hr) } \\
\cline { 2 - 6 } & $\mathbf{4 8}$ & $\mathbf{7 2}$ & $\mathbf{9 6}$ & $\mathbf{1 2 0}$ & $\mathbf{1 4 4}$ \\
\hline Aspergillus niger 6A & 43.4 & 54.4 & 70.8 & 88 & 121.4 \\
\hline Aspergillus niger NRC & 10.6 & 52.4 & 54.6 & 112 & 81.2 \\
\hline Aspergillus niger NRRL & 60.4 & 71.2 & 86.6 & 78 & 72.8 \\
\hline Aspergillus oryzae & 10.4 & 14.6 & 25.6 & 44.4 & 45.8 \\
\hline Aspergillus fumigatus & 35 & 54.4 & 56.4 & 48.2 & 27 \\
\hline
\end{tabular}

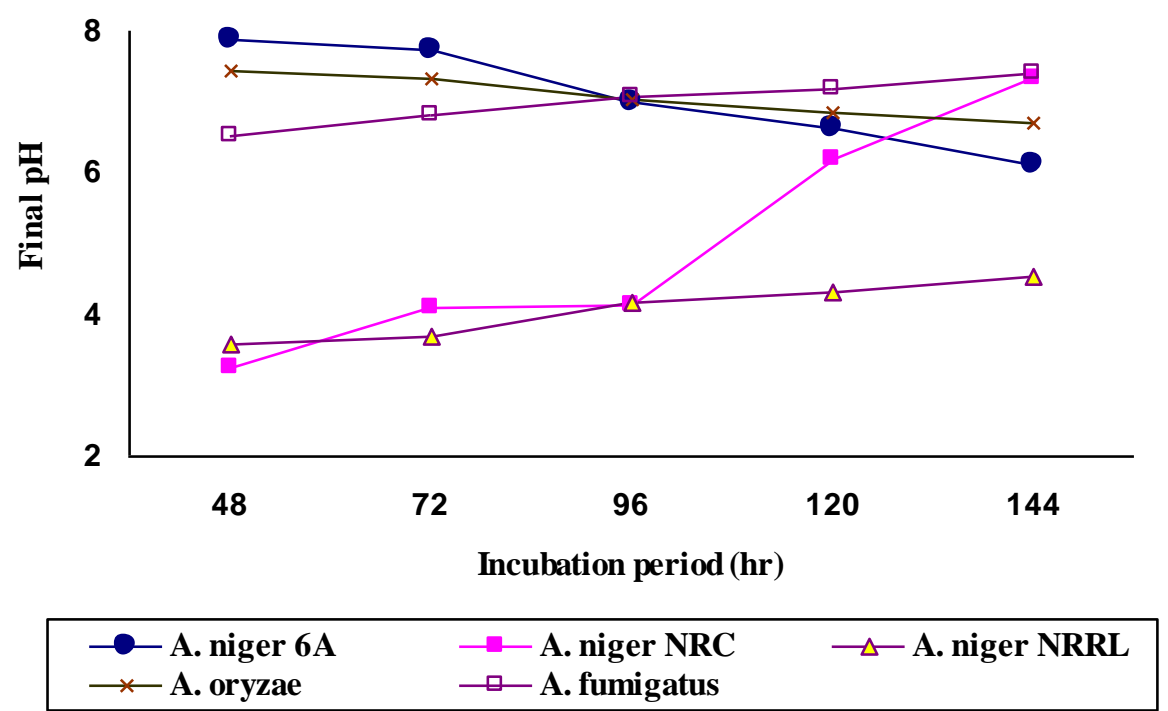

Fig.1: Effect of dahlia tubers addition on final $\mathrm{pH}$ of inulinase production by selected fungal srtains.

The more effect was found with $A$. niger NRC and $A$. niger $6 \mathrm{~A}$ since inulinase activity was increased by $118.75 \%$ and $93.93 \%$, respectively. The lowest values of inulinase activities were found with Aspergillus niger NRRL, $A$. fumigatus and $A$. oryzae since the increase percent were found to be $51.39 \%, 27.03 \%$ and $4.09 \%$, respectively. These results are in agreement with those obtained by Sharma et al., (2006) who reported that, the enzyme 
activity was about 1.6-fold higher than activity that obtained by using pure inulin as a carbon source.

Complex substrates from plant materials, plant materials vegetal substrate are showing very interesting results for inulinase production. Roots and tubers of several plants belonging to families Compositae and Liliaceae have been reported to be good sources of inulin. Among these, Dahlia tubers and dahlia extract were used as a substrate for both cell cultures and inulinase production by several authors (Gill et al., 2006; Sharma et al., 2006; Singh et al., 2006; Singh et al., 2007; Kango, 2008; Singh \& Bhermi, 2008 and Chen et al., 2009).

Effect of Girasole addition on inulinase production by selected fungal srtains.

Table 2 show the effect of Girasole addition on inulinase production by selected fungi. The highest values of inulinase production were by $A$. niger NRC, A. niger 6A, A. niger NRRL, $A$. oryzae and A. fumigatus were 110, 95.4, 83.6, 54.6 and $48.4 \mu \mathrm{g}$ fructose $/ \mathrm{ml}$, respectively. The determined inulinase activities were found to correlate with $120 \mathrm{~h}$ of incubation except $A$. fumigatus was found at $96 \mathrm{~h}$. These values of inulinase activities were found to correlate with the final $\mathrm{pH}$ values being $6.41,4.33,3.17,6.43$ and 6.52 , respectively (Fig. 2).

Table 2: Inulinase activities by selected fungal strains as induced by Girasole.

\begin{tabular}{|l|c|c|c|c|c|}
\hline \multirow{2}{*}{ Fungal srtains } & \multicolumn{5}{|c|}{ Incubation period (hr) } \\
\cline { 2 - 6 } & $\mathbf{4 8}$ & $\mathbf{7 2}$ & $\mathbf{9 6}$ & $\mathbf{1 2 0}$ & $\mathbf{1 4 4}$ \\
\hline Aspergillus niger 6A & 75.6 & 76.2 & 94 & 95.4 & 96.2 \\
\hline Aspergillus niger NRC & 24 & 34 & 41.2 & 110 & 67.2 \\
\hline Aspergillus niger NRRL & 44.8 & 45.4 & 48.2 & 76.4 & 83.6 \\
\hline Aspergillus oryzae & 23.8 & 32 & 42.2 & 54.6 & 30 \\
\hline Aspergillus fumigatus & 29 & 40.6 & 48.4 & 40 & 38.8 \\
\hline
\end{tabular}

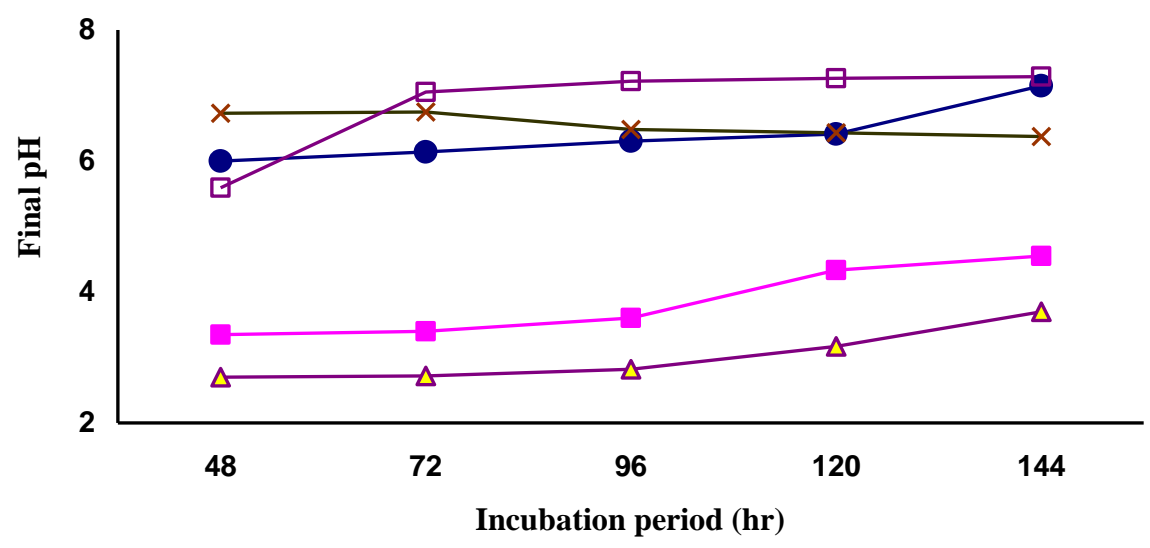

\begin{tabular}{|ll|}
\hline- A. niger 6A & - A. niger NRC \\
$\rightarrow$ A. oryzae & $\square$ A. fumigatus
\end{tabular}


Huka, F. I. A. et al.

Fig. 2: Effect of Girasole addition on final pH of inulinase production by selected fungal srtains.

The effects of Girasole addition on inulinase production had the same effect which occured with Dahlia tubers addition compared with crude inulin and it also varied according to the fungal srtains. The highest effect was also found with $A$. niger NRC 121.4 and the lowest values were 52.40, 33.57, 24.09 and 9.01 for $A$. niger $6 \mathrm{~A}, A$. niger NRRL $A$. oryzae and $A$. fumigatus, respectively.

Effect of chicory addition on inulinase production by selected fungal srtains.

Table 3 show the effect of chicary addition on inulinase production by selected fungi. The highest values of inulinase activities obtained by $A$. niger 6A, A. niger NRRL, A. niger NRC, A. fumigatus and $A$. oryzae were 64.2, $55.8,40.4,35.4$ and $24.2 \mu \mathrm{g}$ fructose $/ \mathrm{ml}$, respectively. These values of inulinase activities were detected after $144,120,120,48$ and $144 \mathrm{~h}$ of incubation. The determined inulinase activities were found to correlate with the final $\mathrm{pH}$ being $6.25,6.20,3.65,6.54$ and 6.66 (Fig. 3).

Table 3. inulinase activity by selected fungal strains as induced by Chicory.

\begin{tabular}{|l|c|c|c|c|c|}
\hline \multirow{2}{*}{ Fungal srtains } & \multicolumn{5}{|c|}{ Incubation period (hr) } \\
\cline { 2 - 6 } & $\mathbf{4 8}$ & $\mathbf{7 2}$ & $\mathbf{9 6}$ & $\mathbf{1 2 0}$ & $\mathbf{1 4 4}$ \\
\hline Aspergillus niger 6A & 40.4 & 41.4 & 45.2 & 54.2 & 64.2 \\
\hline Aspergillus niger NRC & 16.2 & 19.8 & 25.4 & 40.4 & 40 \\
\hline Aspergillus niger NRRL & 40.6 & 44.8 & 51.4 & 55.8 & 54.4 \\
\hline Aspergillus oryzae & 8 & 12 & 14 & 17 & 24.2 \\
\hline Aspergillus fumigatus & 35.4 & 30.2 & 18.8 & 3 & 0.88 \\
\hline
\end{tabular}

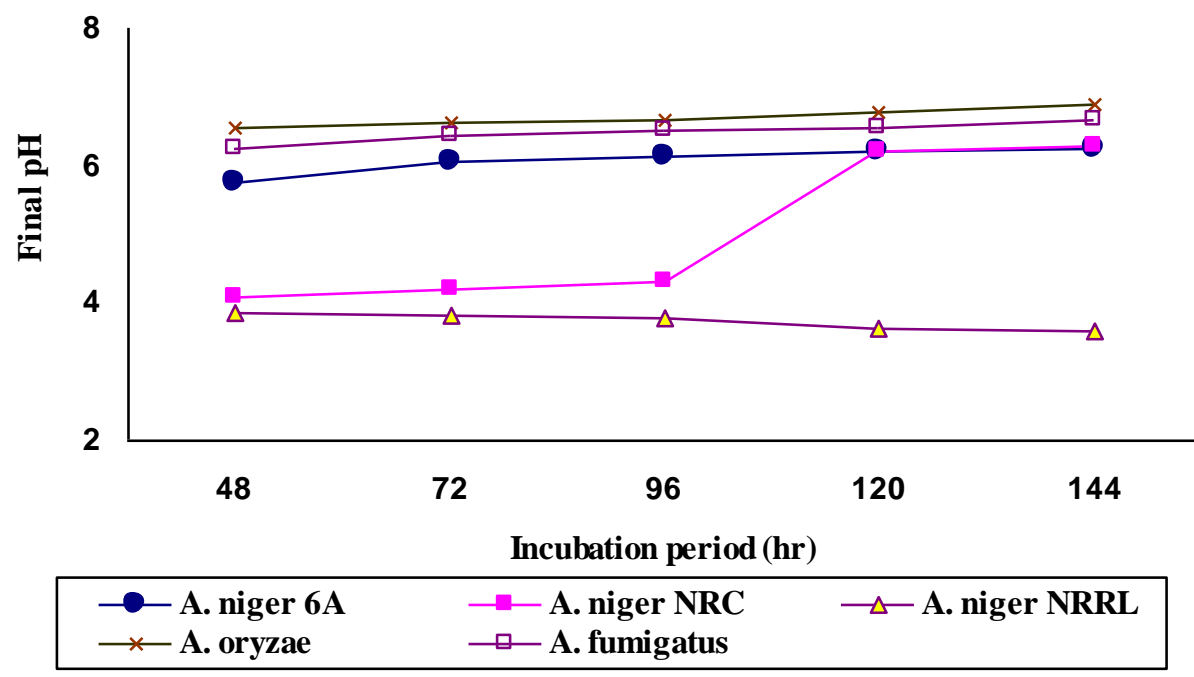

Fig. 3: Effect of chicory addition on final $\mathrm{pH}$ of inulinase production by selected fungal srtains. 
Effect of alkhrishv addition on inulinase production by selected fungal srtains.

Table 4 show the effect of alkhrishv addition on inulinase production by selected fungi. The highest values of inulinase activities produced by $A$. niger NRRL, $A$. niger $6 \mathrm{~A}, A$. fumigatus, $A$. oryzae and $A$. niger NRC were 77.6, 64.2, 44.4, 41.4 and $46 \mu \mathrm{g}$ fructose $/ \mathrm{ml}$, respectively. These activities were detected after 144, 96, 120, 96 and $96 \mathrm{~h}$ of incubation. The inulinase activities were found to correlate with the final $\mathrm{pH}$ were $6.10,4.13,4.60,7.66$ and 7.60 (Fig. 4).

Decrease in inulinase activities can be due to catabolic repression of the enzyme synthesis by high concentration of simple sugars obtained in cultivation medium as a result of inulinase activities. Alkhrishv is commonly produced high levels of fermentable sugars. High glucose concentration repressed fermentation activity dramatically (Singh et al., 2006; Sirisansaneeyakul et al., 2006; Kango, 2008; Singh \&Bhermi, 2008; Ge et al., 2009; Bonciu et al., 2010, and Zhang et al., 2010).

Table 4. Inulinase activities by selected fungal strains as induced by alkhrishv

\begin{tabular}{|l|c|c|c|c|c|}
\hline \multirow{2}{*}{ Fungal srtains } & \multicolumn{5}{|c|}{ Incubation period (hr) } \\
\cline { 2 - 6 } & $\mathbf{4 8}$ & $\mathbf{7 2}$ & $\mathbf{9 6}$ & $\mathbf{1 2 0}$ & $\mathbf{1 4 4}$ \\
\hline Aspergillus niger 6A & 18.6 & 27 & 31.4 & 54.2 & 64.2 \\
\hline Aspergillus niger NRC & 10.6 & 36.6 & 46 & 31.8 & 25.6 \\
\hline Aspergillus niger NRRL & 27.8 & 37.8 & 74.6 & 77.6 & 59.8 \\
\hline Aspergillus oryzae & 5.2 & 26 & 41.4 & 28.6 & 14.4 \\
\hline Aspergillus fumigatus & 27.8 & 34.4 & 44.4 & 36 & 34.6 \\
\hline
\end{tabular}

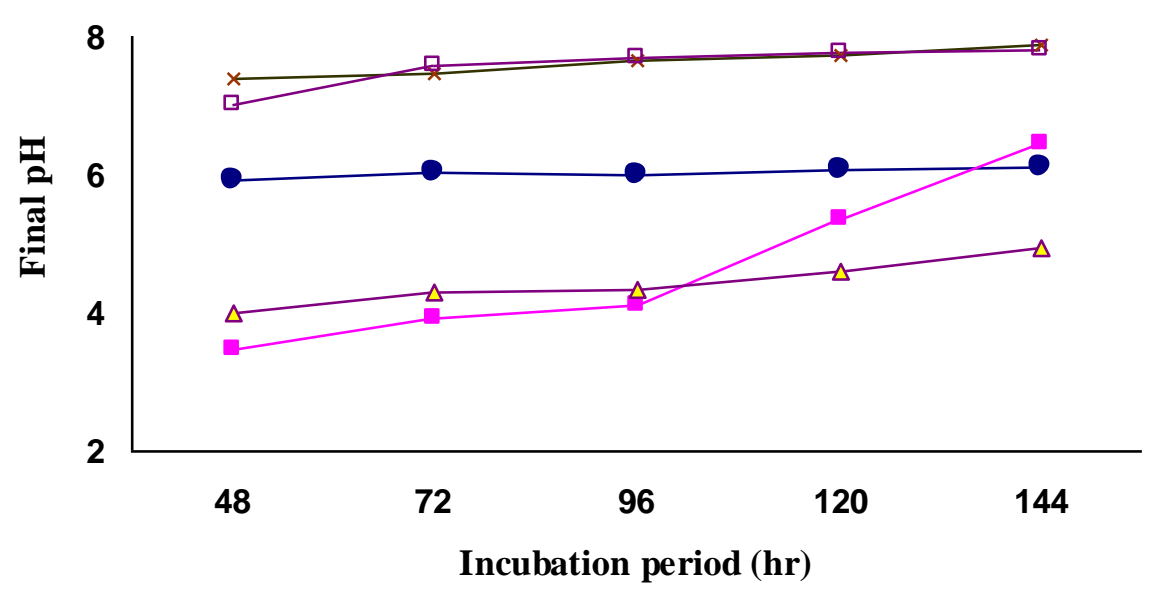

\begin{tabular}{|c|c|c|}
\hline $\begin{array}{l}-\because \text { A. niger } 6 A \\
\longrightarrow \text { A. oryzae }\end{array}$ & $\begin{array}{l}- \text { A. niger NRC } \\
- \text { A. fumigatus }\end{array}$ & $\longrightarrow \triangle$ A. niger NRRL \\
\hline
\end{tabular}

Fig. 4: Effect of alkhrishv addition on final pH of inulinase production by selected fungal srtains. 
Huka, F. I. A. et al.

Also, obtained results are in a good line with those results obtained by the previous authors, where alkhrishv addition had two effect on inulinase production compared with crude inulin. The first was caused a good effect on $A$. niger NRRL and $A$. niger $6 \mathrm{~A}$ since the activity increase by $35.66 \%$ and $2.56 \%$ compared with crude inulin, respectively. The second was caused no effect and obtained values were $0.0,-6.76$ and $-10.16 \%$ for $A$. fumigatus, $A$. oryzae and $A$. niger NRC, respectively.

Effect of sugar beet addition on inulinase production by selected fungal srtains.

Table 5 show the effect of sugar beet addition on inulinase production by selected fungi. The highest values of inulinase produced by $A$. niger NRRL, $A$. niger 6A, $A$. niger NRC, $A$. oryzae and $A$. fumigatus, were 68.2, $59.2,35.6,32.8$ and $28.6 \mu \mathrm{g}$ fructose $/ \mathrm{ml}$, respectively. These activities were found after 120, 48, 144, 48 and $48 \mathrm{~h}$ of incubation. These inulinase activities were found to correlate with the final $\mathrm{pH}$ of the cultivation medium to be 6.55 4.18, 3.46, 6.80 and 5.53 (Fig. 5).

Table 5: Inulinase activity by selected fungal strains as induced by sugar beet.

\begin{tabular}{|l|c|c|c|c|c|}
\hline \multirow{2}{*}{ Fungal srtains } & \multicolumn{5}{|c|}{ Incubation period (hr) } \\
\cline { 2 - 6 } & $\mathbf{4 8}$ & $\mathbf{7 2}$ & $\mathbf{9 6}$ & $\mathbf{1 2 0}$ & $\mathbf{1 4 4}$ \\
\hline Aspergillus niger 6A & 59.2 & 51.2 & 43.4 & 34.6 & 24.8 \\
\hline Aspergillus niger NRC & 14.4 & 17.8 & 21.4 & 22.2 & 35.6 \\
\hline Aspergillus niger NRRL & 37.6 & 39.6 & 57.2 & 68.2 & 64.8 \\
\hline Aspergillus oryzae & 32.8 & 25.2 & 19 & 3.2 & 3 \\
\hline Aspergillus fumigatus & 28.6 & 17 & 13 & 7.4 & 3.4 \\
\hline
\end{tabular}

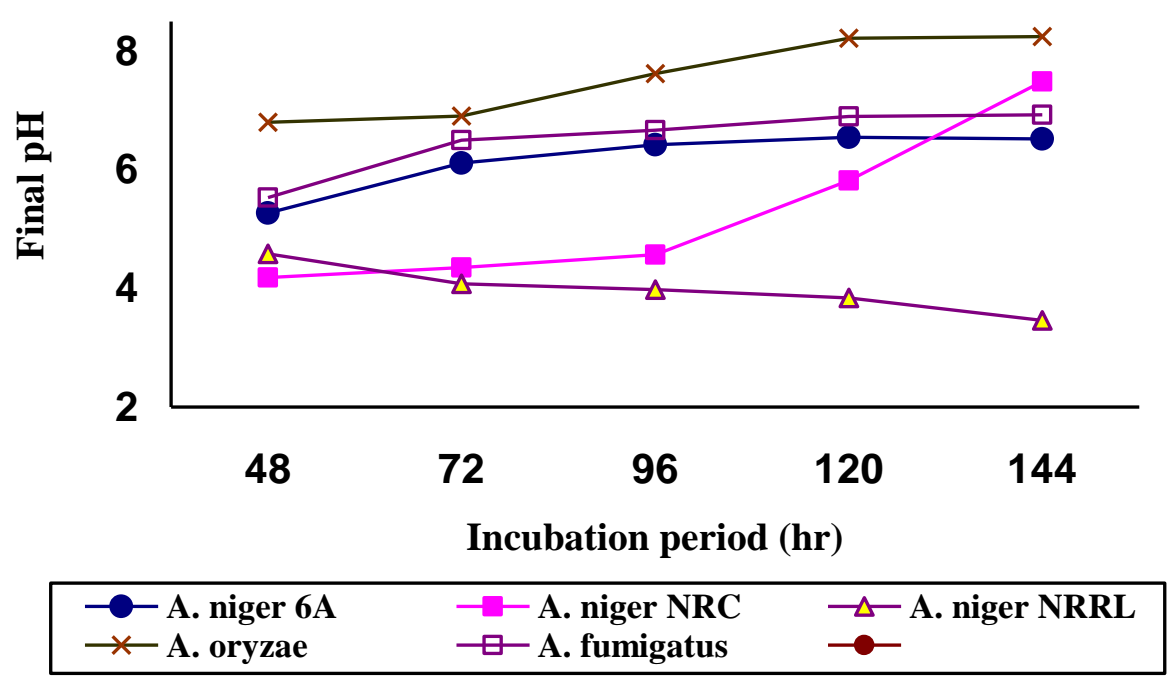

Fig. 5: Effect of sugar beet addition on final $\mathrm{pH}$ of inulinase production by selected fungal srtains. 
The effects of sugar beet addition on inulinase production had the same pattern which occured with alkhrishv addition and it also caused both decrease and increase of inulinase activities produced. The first was caused a good effect on $A$. niger NRRL $19.23 \%$ compared with crude inulin. The second was no effect and values were $-5.43,-25.45,-30.47$ and $-34.70 \%$ for $A$. niger $6 \mathrm{~A}, A$. oryzae, $A$. niger NRC and $A$. fumigatus, respectively.

It could be observed from obtained results that, dahlia tubers and Girasole additions were the best inducer for inulin as production amongst other plant materials used. On the other hand, chicory, alkhrishv and sugar beet additions had negligible and/or negative effects on inulinase production by the tested fungal strains.

\section{REFERENCES}

Bonciu, C.; V. Struta and G. Bahri. (2010). Isolation and screening of new mould strains able for inulinase biosynthesis and inulin from jerusalem artichoke hydrolysis. Innovative Romanian Food Biotechnology. 7 : 7781.

Cazetta, M. L.; P. M. M. Martins; R. Monti and J. Contiero. (2005). Yacon (Polymnia sanchifolia) extract as a substrate to produce inulinase by Kluyveromyces marxianus var. bulgaricus. J. Food Engin., 66: 301305.

Chen, H. Q.; X. M. Chen; T. X. Chen; X. M. Xu and Z. Y. Jin. (2011). Extraction optimization of inulinase obtained by solid state fermentation of Aspergillus ficuum JNSP5-06. Carbohydrate Polymers. 85: 446-451.

Chen, H. Q.; X. M. Chen; Y. Li; J. Wang; Z. Y. Jin; X. M. Xu; J. W. Zhao; T. X. Chen and Z. J. Xie. (2009). Purification and characterisation of exoand endo-inulinase from Aspergillus ficuum JNSP5-06. Food Chemistry. 115: 1206-1212.

Chi, Z. M.; T. Zhang; T. S. Cao; X. Y. Liu; W. Cui and C. H. Zhao. (2011). Biotechnological potential of inulin for bioprocesses. Biores. Technol., 102: 4295-4303.

Cui, W.; Q. Wang; F. Zhang; S. Zhang; Z. Chi and C. Madzak. (2011). Direct conversion of inulin into single cell protein by the engineered Yarrowia ipolytica carrying inulinase gene. Process Biochem. 46: 1442-1448.

Dilipkumar, M.; M. Rajasimman and N. Rajamohan. (2011). Optimization of Inulinase Production from Garlic by Streptomyces sp. in solid state fermentation using statistical designs. Biotechnol. Res. Intern., 43: 1-7.

Ge, X. Y.; H. Qian and W. G. Zhang. (2009). Improvement of L-lactic acid production from Jerusalem artichoke tubers by mixed culture of Aspergillus niger and Lactobacillus sp. Biores. Technol., 100: 18721874.

Gill, P. K.; R. K. Manhas and P. Singh. (2006). Hydrolysis of inulin by immobilized thermostable extracellular exoinulinase from Aspergillus fumigatus. J. Food Engin., 76: 369-375. 
Huka, F. I. A. et al.

Kango, N. (2008). Production of inulinase using tap roots of dandelion (Taraxacum officinale) by Aspergillus niger. J. Food Engin., 85: 73478.

Kumar, G. P.; A. Kunamneni; T. Prabhakar and P. Ellaiah. (2005). Optimization of process parameters for the production of inulinase from a newly isolated Aspergillus niger AUP19. Wold J Microbiol. Biotechnol., 21:.1359-1360.

Nelson, N. (1944). A photometric adaptation of the Somogyi method for the determination of glucose. J. Biol. Chem., 153: 375-380.

Pintado, J.; M. P. González and M. A. Murado (1997). Interactions between pretreatment and nutrient concentrations of mussel processing for citric acid production. Enzyme and Microbial Technol., 20: 544-549.

Sharma, A. D. and P. K. Gill. (2007). Purification and characterization of heatstable exo-inulinase from Streptomyces sp. J. Food Engin., 79: 11721178.

Sharma, A. D.; S. Kainth and P .K .Gill. (2006). Inulinase production using garlic (Allium sativum) powder as a potential substrate in Streptomyces sp. J. Food Engin. 77: 486-491.

Singh, P. and P.K. Gill. (2006). Production of inulinases: recent advances, Food Technol. Biotechnol. 44 (2): 151-162.

Singh, R. S. and R. P. Singh. (2010). Production of fructooligosaccharides from Inulin by endoinulinases and their prebiotic potential. Food Technol. Biotechnol., 48 (4): 435-450.

Singh, R. S.; B. S. Sooch and M. Puri. (2007). Optimization of medium and process parameters for the production of inulinase from a newly isolated Kluyveromyces marxianus YS-1. Biores. Technol., 98: 25182525.

Singh, R.S. and H.K. Bhermi. (2008). Production of extracellular exoinulinase from Kluyveromyces marxianus YS-1 using root tubers of Asparagus officinalis. Biores. Technol., $99: 7418-7423$.

Singh, R.S.; R. Dhaliwal and M. Puri (2006). Production of inulinase from Kluyveromyces marxianus YS-1 using root extract of Asparagus racemosus. Process Biochemistry, 41: 1703-1707.

Sirisansaneeyakul, S.; N. Worawuthiyanan; W. Vanichsriratana; P. Srinophakun and Y. Chisti. (2006). Production of fructose from inulin using mixed inulinases from Aspergillus niger and Candida guilliermondii. Food Technol. Biotechnol., 48 (4) 435-450.

Zhang, T.; Z. Chi; C. H. Zhao; Z. M. Chi and F. Gong. (2010). Bioethanol production from hydrolysates of inulin and the tuber meal of Jerusalem artichoke by Saccharomyces sp. W0. Biores. Technol., 101: 81668170. 
استخدام مواد نباتية كمصادر لإنتاج إنزيم الإنيولينيز من سلالات فطر الاسبرجيلس

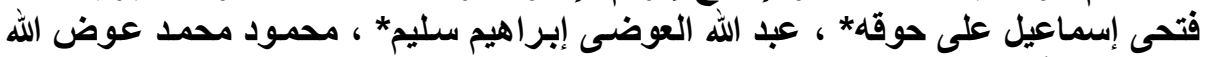

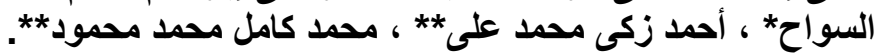

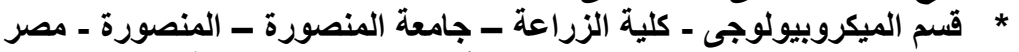

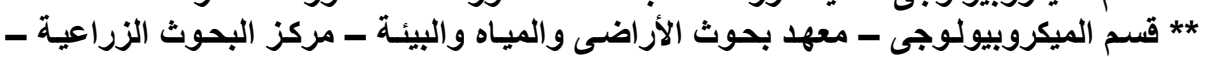

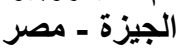

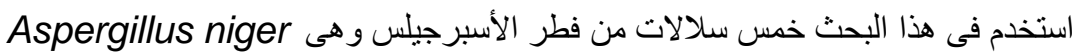
، A. oryzae ، A. fumigatus ، A. niger NRC ، A. niger NRRL ، 6A

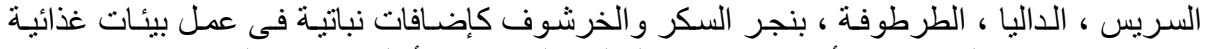

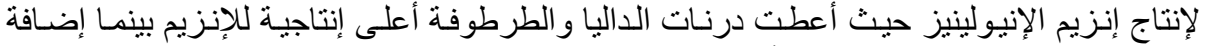
السريس وبنجر السكر والخرشوف أظهرت نتائج اقل فى إنتاج الإنزيم.

كلية الزراعة - جامعة المنصورة كلية زراعة دمياط - جامعة المنصورة
قام بتحكيم البحث

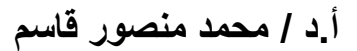
أ.د / حسين عبد الله محمد الفضالي 